\title{
Heat stored in a solid block as source of heating energy
}

\author{
Tibor Horváth*, Zoltán Pásztory \\ ${ }^{a}$ Innovation Center, University of West Hungary, Sopron, 9400, Hungary
}

\begin{abstract}
In present work, the possibility was explored to use a solid block for space heating. The block was placed in a test house with low energy characteristics. Computations revealed that heating period greatly depended on the rate of heat withdrawal. With a rate of $122 \mathrm{~W}$, the required indoor temperature $\left(20^{\circ} \mathrm{C}\right)$ could be maintained for a heating period of 150 days. Larger part of stored energy used for space heating by heat seepage through the block insulation ( 48\%) and by withdrawing the heat $(\sim 38 \%)$. Loss to the ground amounted to $\sim 14 \%$ of the total energy content of block $(\sim 3.5$ GJ). This experiment substantiated the viability of space heating by a thermal energy storage system. The heating block had the ability to provide $8.28 \mathrm{kWh} /\left(\mathrm{m}^{2} \cdot \mathrm{yr}\right)$ which is a realistic scenario with regards to the heating demands of passive houses. Finite element method proved to be very useful for simulation scenarios.
\end{abstract}

Keywords: Heat loss, insulation, low energy house, space heating, thermal energy storage

\section{Introduction}

In the European Union, buildings are responsible for about $40 \%$ of the total energy consumption and for $30 \%$ of $\mathrm{CO}_{2}$ emission [1], [2]. In residential homes, about $82 \%$ of the total energy requirement is used for space heating and hot water production [3], [4].

In this paper, solar energy has been considered as source for space heating which is available in larger amount rather in summer, whereas demand for heating arises essentially in winter. Thus, the need for seasonal Thermal Energy Storage (TES) surfaced already as early as the 1940s [5], and developmental works have been conducted since. There is a very good review about the theoretical background and according systems available in the literature [5]-[7].

As regards the storage mechanism, there are (thermo-)chemical, latent, and sensible heat storage systems [6], [8], [9]. A sensible TES system makes use of the high heat capacity of a materials, stores thermal energy in form of heat. It also operates in a wider temperature range than the other two. For the sensible TES, the most widely used storing materials are water and rock [10]. In general, this type of TES system is cheaper than the other ones. The heat density in the medium is, however, considerably lower than in the other types, and for this reason, the sensible TES system is larger and heavier than chemical and latent ones. In order to contain the heat in the system at high storage temperature, very good insulation and a low surface to volume ratio are required [5]. Proper sizing of thermal energy storage systems can be derived by modeling the thermal behavior of the storage blocks [11], [12].

The objective of present investigation was to model the cooling-down process of a thermal energy storage system, heated up in the summer season by electric energy which had been gained from solar panels. In particular, the dependence of the heating period length on the starting temperature of the storing block as well as on the heat withdrawal scenarios, under inclusion of the insulation characteristics of the enclosure and the house, was of central interest. This interdependence has been analyzed with the help of a Finite Element Method (FEM).

\footnotetext{
* Manuscript received April 2, 2015; revised June 3, 2015.

Corresponding author. Tel.: +36-20-268-2820; E-mail address: horvath.tibor@emk.nyme.hu.

doi: $10.12720 /$ sgce.4.2.119-124
} 


\section{Material and Methods}

\subsection{Modeling}

For this study, a low-energy residential home was tested which has fulfilled the space heating requirements of a passive house, i.e., its energy consumption has not surpassed $15 \mathrm{kWh} /\left(\mathrm{m}^{2} \cdot \mathrm{yr}\right)$. The experimental house, built specifically for such experiments, was located in a temperate climate zone. Thus, the yearly energy consumption for space heating of this house with a surface area $120 \mathrm{~m}^{2}$ would amount at the most to $1800 \mathrm{kWh} / \mathrm{yr}$. If the insulation characteristics of the house could be improved in such a manner that the heat demand was be reduced to $1440,1080,720$, and $360 \mathrm{kWh} / \mathrm{yr}$, respectively, the question arises as to the rate of the heat withdrawal. For the experiment, the needed energy was supplied by a heat block with a given amount of heat content. In the model, a constant rate of energy withdrawal was presumed, i.e., possible daily and seasonal variations of heating demand were ignored.

The thermal behavior of heat block was modeled with finite element method software COMSOL Multiphysics ${ }^{\circledR}$. To simulate the cooling-down process, a time dependent model with 3D geometry was used. The applied differential equation for pure heat conduction without heat source is the following:

$$
\rho C_{p}(\partial T / \partial t)+\nabla \cdot(-\lambda \nabla T)=0
$$

Here, $\rho, C_{p}$, $\lambda$, and $T$ stand for density, specific heat capacity, thermal conductivity and temperature, respectively. $\nabla$ is the differential operator (nabla) and $t$ is the time.

The energy storing unit is composed of a silicate based solid block, formed as a box. Its dimensions were of $4.20 \mathrm{~m} \times 1.40 \mathrm{~m} \times 1.95 \mathrm{~m}$ (length $\times$ width $\times$ height). To minimalize heat loss, it was surrounded by a three-layered insulation wall with properties shown in Table 1 .

Table 1. Thermal properties of the structural elements of heat container

\begin{tabular}{lcccc}
\hline $\begin{array}{l}\text { Name of } \\
\text { structural } \\
\text { element }\end{array}$ & Thickness & Density & Heat capacity & $\begin{array}{c}\text { Thermal } \\
\text { conductivity } \\
\lambda(\mathrm{W} / \mathrm{m} \cdot \mathrm{K})\end{array}$ \\
\hline Core & $d(\mathrm{~m})$ & $\rho\left(\mathrm{kg} / \mathrm{m}^{3}\right)$ & $C_{p}(\mathrm{~J} / \mathrm{kg} \cdot \mathrm{K})$ & 1.5 \\
Layer-1 & - & 2285 & 810 & 0.020 \\
Layer-2 & 0.1 & 230 & 800 & $\lambda_{\text {Layer-2 }}=f(T)$ \\
Layer-3 & 0.28 & 105 & 840 & 0.022 \\
\hline
\end{tabular}

Table 1 indicates that every insulation layer has a low thermal conductivity. Accordingly, one can expect hardly changing heat transfer rates which are assumedly the case with the insulation layers Layer-1 and Layer-3. The Layer-2 is exceptional in terms of being temperature dependent where the thermal conductivity markedly changes from $0.038 \mathrm{~W} /(\mathrm{m} \cdot \mathrm{K})$ at $30^{\circ} \mathrm{C}$ to $0.088 \mathrm{~W} /(\mathrm{m} \cdot \mathrm{K})$ at $200^{\circ} \mathrm{C}$. For modeling purposes, the thickness of Layer-2 was also varied, and values of $0.28 \mathrm{~m}, 0.42 \mathrm{~m}, 0.56 \mathrm{~m}$ have been taken into the calculations. The influence of moisture on thermal properties was not included in the simulation. It was, however, supposed that all material properties were isotropic. Perfect contact was assumed between the block surfaces and the insulation layers.

\subsection{Initial and boundary conditions}

The insulated heat block was placed on a concrete slab with known thermal permeability. The temperature of the slab was assumed to be $15^{\circ} \mathrm{C}$, and so the heat leakage towards the ground could be calculated. On all other free sides of the block, the heat loss through the insulation to the surrounding with a temperature of $20^{\circ} \mathrm{C}$ was assumed to be $5 \mathrm{~W} / \mathrm{m}^{2}$, approximated by foregoing measurements. The above mentioned boundary conditions were applied in every steps of the simulation. The initial temperature of the heat block had been raised to $200^{\circ} \mathrm{C}$, an arbitrary decision which can be changed in future according to the outcome of the measurements and the simulation results. With the help of a heat exchanger, where air has been used as heat transporting means, constant rates of heat in time could be withdrawn from the block. 


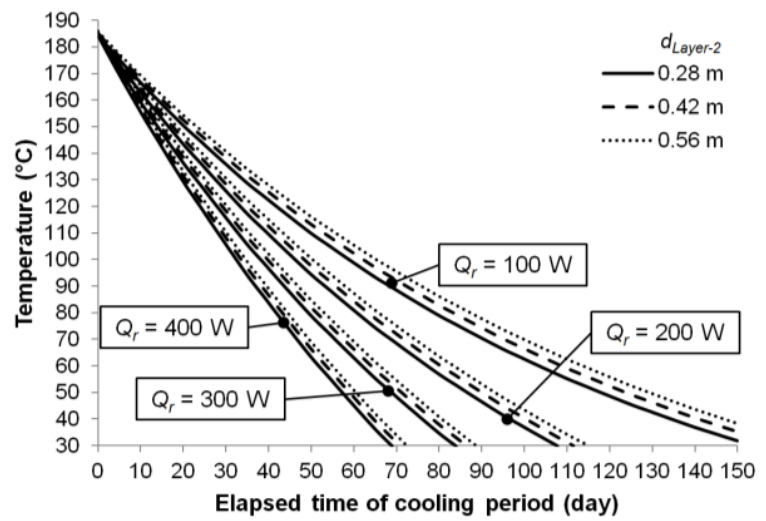

Fig. 1. Cooling down rates of the block with various amounts of heat withdrawal and with variable Layer-2 thicknesses over the simulated time periods.

The rate of heat withdrawal $\left(Q_{r}\right)$ was set to values between $100 \mathrm{~W}$ and $400 \mathrm{~W}$, equaling $360 \mathrm{kWh} / \mathrm{yr}$ and $1440 \mathrm{kWh} / \mathrm{yr}$, respectively, as stated above. Although the simulation time was delimited to 3600 hours (= heating period of 150 days), an experimental run was terminated when the average temperature of block sank below $30^{\circ} \mathrm{C}$.

\section{Results and Discussion}

The time dependent cooling-down process has started at temperature of $200^{\circ} \mathrm{C}$ which could be realized in the core region the block only. For the calculation of the initial temperature distribution, some 15 temperature sensors were placed in the block, and as many in the insulation layers according to a plan. Though, the layer thickness of the Layer-2 physically remained unchanged, $d_{\text {Layer-2 }}=0.28 \mathrm{~m}$, the thickness was virtually altered twice in the simulation. At start, a measurable temperature drop between core and border regions of the block had been measured and used in the model.

In Fig. 1, the change of average block temperature has been simulated over time periods, taking the layers` thicknesses into account. The aim of heating was to keep the room temperature at $20^{\circ} \mathrm{C}$ at all times. The graph shows that the doubling of the Layer-2 thickness exerts only a minor effect on the cooling rate and could be ignored in the following. The course of the cooling curves is hyperbolic and exhibits a strong dependence on the heat withdrawal rate. It also shows that an aggressive heat withdrawal rate rather quickly exhausts the stored energy. At $Q_{r}=400 \mathrm{~W}$ the heating period has been more than halved whereas at $Q_{r}=100 \mathrm{~W}$ the desired room temperature of $20^{\circ} \mathrm{C}$ could be maintained for the full heating period of 150 days.

Table 2. Maximum achievable heating periods (days) at various heat withdrawal rates $\left(Q_{r}\right)$ and Layer-2 thicknesses $\left(D_{\text {Layer-2 }}\right)$

\begin{tabular}{lrrr}
\hline$Q_{r}(\mathrm{~W})$ & \multicolumn{3}{c}{$d_{\text {Layer }-2}(\mathrm{~m})$} \\
& 0.28 & 0.42 & 0.56 \\
\hline 400 & 69 & 71 & 73 \\
300 & 84 & 87 & 89 \\
200 & 108 & 112 & 115 \\
100 & 169 & $>150$ & $>150$ \\
\hline
\end{tabular}

Table 2 displays the maximum attainable period's duration with various heat withdrawal rates from the block, observing the limiting core temperature of $30^{\circ} \mathrm{C}$. Elapsed times are given in days. It can be seen that a decreasing rate of heat withdrawal, e.g., from $400 \mathrm{~W}$ to $300 \mathrm{~W}$, gives a 1.2 times longer heating period. Cutting the heating rate by half, from $400 \mathrm{~W}$ to $200 \mathrm{~W}$, prolongs heating period by a factor of 1.6. Withdrawing only $Q_{r}=100 \mathrm{~W}$, the possible heating period will exceed the set limit of 150 days. Grey 
numbers in Table 2 indicate the results of the calculations with changed Layer- 2 thicknesses which proved to become negligible in the simulation.

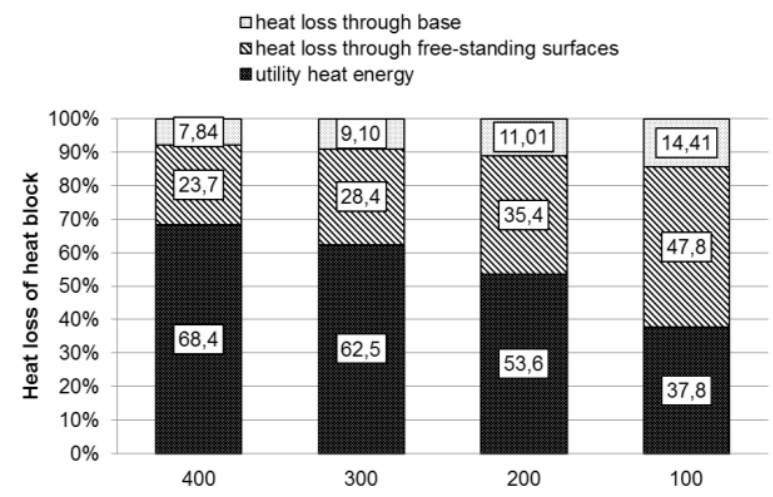

Fig. 2. The ratio of energy types while being withdrawn from the block at the given rates ( $400 \mathrm{~W}$ to $100 \mathrm{~W}$ ).

The heat content of the block is getting reduced in time in following ways:

- Utility heat withdrawal for space heating in the building;

- Heat loss through the insulation walls of the block into the room;

- Heat loss through the base to the ground.

These three energy types add up to the heat content of the block to about 3.5 GJ. This value has been used as starting quantity with all modeling runs. Actually, the utility heat and the losses through the side walls of the block jointly contribute to the space heating. Depending on the withdrawal rate, the losses through the surfaces seem to get bigger as one proceeds from $400 \mathrm{~W}$ to $100 \mathrm{~W}$ because with the latter withdrawal rate more time is available for heat seepage through the insulation walls. With $400 \mathrm{~W}$ withdrawal rate the ratio of useful energy is the highest, being $68.4 \%$, based on the energy total of 3.5 GJ, whereas the heat loss through the side walls amounts to $23.7 \%$, the rest being lost to the ground. With 100 $\mathrm{W}$, the useful energy drops to $37.8 \%$ and the heat loss rises $47.8 \%$ meaning that, according to the model, the room was heated to a larger extent by the heat seepage through the insulation walls and to a smaller one through the direct heating system. Fig. 2 makes these relations evident.



Fig. 3. Exhausting time of heat block as the function of energy withdrawal.

Having all data at hand, it is possible to determine the heat withdrawal rate which would satisfy the boundary conditions, i.e., room temperature of $20^{\circ} \mathrm{C}$, length of the heating period of 150 days, heat content of the block $\sim 3,5 \mathrm{GJ}$, insulation characteristics of the house and of the heating system as given. Fig. 3 illustrates this interdependence. Using the equation in Fig. 3, the recommended heat withdrawal rate from the heat block is about $122 \mathrm{~W}$ (fat dot in the graph) to which the amount of heat, leaked through 
the insulation into the room, i.e., $154 \mathrm{~W}$ must be added. The total of $276 \mathrm{~W}$ would match the above boundary conditions. The value of $276 \mathrm{~W}$, transformed into $8.28 \mathrm{kWh} /\left(\mathrm{m}^{2} \cdot \mathrm{yr}\right)$, compares very favorably with the yearly heating energy requirement of a passive house, presently set to $15 \mathrm{kWh} /\left(\mathrm{m}^{2} \cdot \mathrm{yr}\right)$. The simulation states that it was possible to use a seasonal heat storage system for residential house heating.

\section{Conclusions}

Objective of this study was firstly to investigate the heat release characteristics of a solid block, previously heated to $200^{\circ} \mathrm{C}$, as a possible energy storage system for house heating. Secondly, it was of interest to simulate the temperature distribution in this block using the finite element method. Both questions could be positively answered. The results showed that it was possible to withdraw heat from the block in a controlled manner while maintaining a constant temperature of $20^{\circ} \mathrm{C}$ in the house. The withdrawal rate was predictably lowering the heat content of the block. Too fast a rate such as $400 \mathrm{~W}$, 300 , or $200 \mathrm{~W}$, however, exhausted the stored heat in a shorter time as the set heating period. Only with a withdrawal rate of $122 \mathrm{~W}$, it was possible to maintain the desired room temperature of $20^{\circ} \mathrm{C}$ for 150 days without prematurely exhausting the heat reserve. As a side effect, it could be also shown that the variation of the thickness of insulating layers (Layer-2) had a negligible effect on the heat reduction of the block.

The total heat content of the block, having a starting temperature of $200^{\circ} \mathrm{C}$ and final of $30^{\circ} \mathrm{C}$ amounted to approximately $3.5 \mathrm{GJ}$. At the recommended withdrawal rate, the utilizable heat for keeping the room temperature at $20^{\circ} \mathrm{C}$ accounted to slightly more than $38 \%$. A large portion of about $48 \%$ was dissipated by drainage through the insulation walls, though this has still contributed to the room heating. The heat loss to the ground of about $14 \%$ represents the irrecoverable part of the total energy amount. In conclusion, the heating block had the ability to provide $8.28 \mathrm{kWh} /\left(\mathrm{m}^{2} \cdot \mathrm{yr}\right)$ which is a realistic scenario with regards to the heating demands of passive houses.

The investigation has thus proven that a pre-heated solid block in a house properly insulated, and furnished with an apt withdrawal system can provide heating energy for the required period of time.

Future research works shall deal with details of the heating system, and, not at last, with the economics of such a system.

\section{Acknowledgements}

This study was supported by the Environment conscious energy efficient building TAMOP-4.2.2.A11/1/KONV-2012-0068 project sponsored by the EU and European Social Foundation. We express our cordial thanks to Mihály Bariska for his useful suggestions on the manuscript.

\section{References}

[1] Anonym. Report on the green paper on energy or doing more with less. Research report. European Commission, Brussels, Belgium, 2005.

[2] Directive 2010/31/EU of the european parliament and of the council of 19 May 2010 on the energy performance of buildings. [Online]. Available: http://eur-lex.europa.eu/LexUriServ/LexUriServ.do?uri=CELEX:32010L0031:EN:NOT

[3] Gordon VR, Holness PE. Improving energy efficiency in existing buildings. ASHRAE Journal, 2008;50(1):12-26.

[4] Linder S, Bhar R. (2007). Space conditioning in the residential sector in Europe, Deliverable 1 Ground Reach EU project. Ecofys. [Online]. Available: http://ec.europa.eu/energy/intelligent/projects/sites/iee-projects/files/projects/documents/groundreach_space_conditioning_in_the_residential_sector.pdf

[5] Pinel P, Cruickshank CA, Beausoleil-Morrison I, Wills A. A review of available methods for seasonal storage of solar thermal energy in residential applications. Renewable and Sustainable Energy Reviews, 2011;15(7):3341-3359.

[6] Dincer I, Rosen MA. Thermal Energy Storage: Systems and Applications. 2nd ed. Chichester: Wiley; 2011.

[7] Agyenim F, Hewitt N, Eames P, Smyth M. A review of materials, heat transfer and phase change problem formulation for latent heat thermal energy storage systems (LHTESS). Renewable and Sustainable Energy Reviews, 2010;14(2):615-628.

[8] Dincer I. On thermal energy storage systems and applications in buildings. Energy and Buildings, 2002;34(4):377-388.

[9] Ismail KAR, Stuginsky Jr R. A parametric study on possible fixed bed models for PCM and sensible heat storage. Applied Thermal Engineering, 1999;19(7):757-788. 
[10] Oliveski RC, Krenzinger A, Vielmo HA. Comparison between models for the simulation of hot water storage tanks. Solar Energy, 2003;75(2):121-134.

[11] Wu H, Wang S, Zhu D, Ding Y. Numerical analysis and evaluation of an open-type thermal storage system using composite sorbents. International Journal of Heat and Mass Transfer, 2009;52(21-22):5262-5265.

[12] Giestas MC, Pina HL, Milhazes JP, Tavares C. Solar pond modeling with density and viscosity dependent on temperature and salinity. International Journal of Heat and Mass Transfer, 2009;52(11-12):2849-2857. 